\title{
Market orientation - a pertinent solution in reevaluating traditional marketing
}

\author{
Luminita Zait, „Vasile Alecsandri” University of Bacau, Romania \\ Laura Timiras, „Vasile Alecsandri” University of Bacau, Romania \\ Bogdan Nichifor, „,Vasile Alecsandri” University of Bacau, Romania
}

\begin{abstract}
This article focuses on describing the latest trends in the theoretical and practical development of the marketing concept. Market orientation is the main item discussed, emphasizing the advantages and pitfalls of applying such a specific concept.
\end{abstract}

\section{Keywords}

Marketing, market orientation, evaluating methods

\section{JEL Codes: M 30, M31}

\section{Traditional marketing - some critics}

The failure of numerous organizations in the new marketing environment of the $20^{\text {th }}$ and the beginning of the $21^{\text {th }}$ century has generated a number of critics regarding the efficiency and viability of traditional marketing. Thus, in theory and practice the questions started to appear, the most common being the one associated with necessity of identifying of some new orientation of marketing function, starting from the grown complexity of the markets and emergence of the new values.

The main critics bring to traditional marketing by the academics are related to:

- Traditional marketing stands on a world which is unrecognizable for many marketing managers which currently have to really manage the marketing process (Piercy, 1991);

- Actual marketing concept is unrealistic and has to be rethink (Gummeson, 1987);

- Traditional marketing methods are no longer as efficient as were in the past (Rapp, Collins, 1990);

- Marketing concept, as it was propagated and understand in the past, no longer can assure elements of sustainability in obtaining business success in the context of the end of $20^{\text {th }}$ century (Brownlie, Saren, 1992);

- After studying and disseminating the importance of marketing for a 30 years period, Michael Thomas concluded the he has serious doubts regarding the efficiency of marketing in current context (Thomas, 1993);

- Marketing process, albeit it have being used in the past by numerous organizations, appears to be now far from being appreciated, especially from the point of view of advantages that it may bring (Hooley, Saunders, 1993);

Most of the critics come from where is expected, namely from practice. A series of studies developed in United States of America and Europe (Narver and Slater, 1990; Kohli şi Jaworschi, 1990; Brady and Davis, 1993, George, Freeling and Court, 1994; Lambin, 1996; Webster, 1997; Deshpande, 1998; etc.) revealed a grown lack of satisfaction of different 
sectors marketing managers regarding marketing process and marketing functional structures. Those critics are:

- As the confidence in market orientation process and in its functional integration grow, marketing function has no longer the capacity to sustain the process of disseminating market culture at the organization level;

- The organizations concentration on "action dimensions" or on operational marketing generated unjustified costs, uncovered by performance;

- Traditional marketing has promoted tactical means, opening the way for advertising and sales promotion, but ignoring the process of innovation;

- In the new marketing environment, marketing process and strategic marketing are much too important to be left just in the responsibility of the marketing function;

- Aversion on the risk, present in numerous organizations, favored minor innovations, asked by the market, and not breaking innovations based on technology and creativity;

- Marketing reactions regarding green movements was not the expected one; responding to the pressure of ecological entities by using advertising and not by creating new products concepts, traditional marketing risked to undermine the credibility of green marketing;

- By neglecting the segment of simplified products with low prices, traditional marketing favored the entry of big retailers on the market which currently control numerous segments with their own brands;

- Weak contribution of traditional marketing in developing and maintaining cooperation relationships with big retailers generated loses on important markets, especially in FMCG markets.

In the context of this analysis, it has to be mentioned that the critics doesn't argue against the marketing as it is, but against the marketing function, as it is organized at the level of the organization; both practitioner and academics agree that marketing functions has to be reinvented in a way which to fortify the market orientation of the whole organization.

\section{Marketing orientation as the new way}

Following the critics bring to marketing, it seems that exist a strong path for sustaining the redefining of this concept and its role in the $21^{\text {th }}$ century.

For most of practitioners the need of changing marketing orientation has emerged as a follow up of fundamental changes in world's markets. These fundamental changes are: the decline of megabrands as a results of price based competitors, the replacement of marketing personnel with the one specialized in undertaking specific tasks, the decline of demand for marketing specialists, the emergence of a new type of consumer which asks for greater value, the presence of a more stratified and aggressive competitors.

On the other hand, for academics the necessity of changing marketing view has been revealed by a series of studies which showed a link between market orientation and organizational performances. In this direction, marketing theory sustains the hypothesis of existence of an significant link between the intensity of market orientation and economic performance: "an organization which step toward a superior level of marketing organization improve its economic performance (Noble, sinha, Kumar, 2002)". Support for this hypothesis come from numerous studies:

- After examining the realities of 1504 British companies, Hooley and Linch concluded that the most efficient organizations are characterized by assuming a coherent orientation toward market, a heedful strategic planning and concentration on products quality (Hooley, Lynch, 1985).

- In 1990, Narver and Slater realized a study which had the objective of identifying the level of market orientation of a group of 140 strategic units of some American 
companies; following this study, the authors concluded that exist a strong relationship between market orientation and profitability (Narver, Slater, 1990);

- Kohli and Jaworchi, which took a series of semi-structured interviews in American organizations, discovered that exist a high level of understanding of the three key components of marketing concept: client orientation, coordination and profitability and the advantages of marketing philosophy can be translated in superior results in terms of performances, in advantages for employers and in favorable attitudes from the consumers;

- Following a study using American, Japanese and British companies sample, Wong and Saunders demonstrated that market oriented organizations - classified as innovators, quality marketers and mature marketers - obtain better results in terms of profit, sales and market share than other organizations classifies as price promoters, products manufacturers and aggressive promoters (Wong, Saunders, 1993);

- A market oriented organization has in general a large number of satisfied clients and as a result a higher fidelity rate and lower sales and prospection costs (Lash, 1990, Dweyr, Schurr, Sejo, 1987);

- A market oriented organization respond better to permanent changing needs by developing new products which renew the portfolio structure and contribute to maintaining an equilibrium between the grow and profitability objectives;

- A market oriented organization is better positioned which facilitate the identifying and selection of the competitive advantage as a way to preserve and amplify the market share (Porter, 1985);

- A market oriented organization develop products which bring to consumers a superior value over the market average, which in turn reduce consumers sensibility to price and grow the level of maximal prices accepted by the market (Nagle, Holden, 1994);

These conditions when reunited directly or indirectly contribute to economic and competitive performance. Concluding, we can say that the base hypothesis of this concept is the next one: market oriented organization allocate human and financial resources for: a. bringing together the data about the expectances and behaviors of the main market player, these data being used to b. develop action plans oriented towards market needs, c. plans that are put in practice by all organization functions.

On the other hand, a series of authors mention the risk which derives from ignoring this new orientation; the absence of such a culture could generate significant consequences over the organization competiveness and over its capacity to overcome the threats of marketing environment. Thus, a number of aspects have to be considered:

- Interface with environment: knowing that the responsibility of assuring the interface organization - environment is held by marketing function, there is a risk that the changes in macro-environment, such are the socio-demographic ones, to be underestimated by other organizational functions. In this context, the question which appear is related to the credibility, the capacity and the power of marketing structure and especially of product manager to generate changes at the organization level;

- The link between R\&D and innovation: the conflict between marketing structure and R\&D structure, identified even in market oriented organization, ask for a complicated dialog. In this context, the link between inventions and innovations is weak, R\&D activity generating a few number of ideas of new products;

- The process of developing new products: These kinds of decisions ask for contribution of all organizational structures. At the level of non-market oriented organizations, the process of developing new products is controlled by different structures which impose a target price for marketing structure. In a marketing oriented product developing process, the price accepted by the market is the one which states the standard for innovation and constitute the contract which has to be assumed by all R\&D and production structures (Cooper, 1993); 
- Competitive advantage and value chain: according to Porter theory, competitive advantage has to have as a starting point the value chain activities (Porter, 1985). The lack of market oriented culture will generate the risk of funding competitive advantage on minor differentiate elements, with low value for the consumers;

- Developing of relational sales: commercial structure has for a long time the tendency to favor transactional sale, especially in the processes of identifying and getting new clients. Based on the reality that it generates a high level of fidelity, relational sale try to create a durable and mutual profitable relationship with current clients.

Beyond the previous point, a series of questions are present in marketing literature and practice. To answer to the question "Which will prosper in this new context?", some specialists argue that the new comers have a certain competitive advantage because they don't have to defend a history of a previous financial status (Day, 2000-2001). This affirmation is fortified by the realities of business environment, many organizations obtaining real competitive advantages based on market orientation without special financial resources. Moreover, not the size, nor the history are elements which assure success in market, but the superior ability to know, understand and satisfy potential consumers needs.

Many marketing specialist ask themselves which are the most market oriented organization and what is their key in business success? Cannot be said that there are absolute standards, the source of competitive advantage is a better orientation to the market segments in terms of categories identified and their needs as a basis for a rigorous strategic planning. The literature states that there are many theories for a viable business path, the key of that business path being the implementation of a simultaneous orientation towards satisfying the consumers and maximizing the economic efficiency.

However, this orientation should not be regarded as automatic success generating because consumer satisfaction is not sufficient to maximize economic efficiency. Real profitability is based on continuous attempt to retain valuable customers for the organization by building a strong loyalty, as a result of mutual trust, bilateral obligations and intense communication.

Supporting modern organizations need to shift towards the market, Webster offered in 1999 a set of 11 indicators which can help in identifying the level of market orientation of an organization: focus on satisfying customers throughout the organization, commitment to deliver value, the identification and development of distinctive competencies, forming strategic partnerships, develop sustainable relationships with strategic customers, increasing the importance of segmentation, targeting and positioning approaches, use of consumer information as a strategic tool, focusing on providing additional benefits and services to consumers, improvement and innovation efforts, defining quality in terms of customer expectations consumer, commitment to provide the latest information technologies.

The most important models for applying and quantification of the degree of market orientation, however, remain:

- MKTOR scale developed by Narver and Slater in 1990, built on 15 items divided into 3 subscales: orientation towards consumer, orientation towards competitors and interfunctional coordination (Narver, Slater, 1990);

- MARKOR scale developed by Kohli and Jaworschi in 1990 and improved in 1993 by Jaworschi, Kohli and Kumar, based on 20 items that link three issues: market intelligence, dissemination of intelligence and the prompt answer to market needs (Kohli, Jaworschi and Kumar, 1993).

However, how do market-oriented organizations have a greater ability to understand, attract and retain target audience categories? The answer can be found mixing the following components, in the opinion of Day (1990): an outer-oriented culture based on faith, values and behaviors directed towards providing a superior value to consumers and stakeholders, and not least the continued efforts towards discovery of new sources of competitive advantages; distinct skills in market intelligence, networking to target audience and prospective strategic thinking. In other words, market-oriented firms are very familiar with their field of action and are able to establish lasting relationships with customers and other 
interest groups. The configuration of a strong market-oriented organization is recognized when these feature are present: strategic orientation to the market - towards providing higher value, consistency among mentioned features and high flexibility to fold on quickly change business environment.

On the other hand, Slater and Narver argue that market-oriented organizations have the ability to obtain information on the land the action, competitors and consumers, puts this information in a business perspective, decide and take steps to obtain higher value for consumers, and arrange to deliver this value to consumers. According to the theory of the two authors, market orientation calls for: focus on the consumer, intelligence in competitor analysis, inter-functional cooperation and involvement. Regarding intelligence in analysis of competitors, this concept implies that a market-oriented organization recognizes the importance of understanding the actions performed by this category of interest: "obtaining a higher value requires that organization identify and understand the main competitors in terms of strenghts and weaknesses, distinctive capabilities and implementation strategies" (Narver, Slater, 1990). The idea of marketing intelligence is mentioned by Jaworschi and Kohli (1996), and Tadepalli and Avila (1999). Courses of action similar to those of Narver and Slater are proposed by Wilson and Fook, which consider that essential in defining the market orientation are the following requirements: identify consumer needs (responding to questions - What goods and services are purchased? Who buys them? Why do they buy?), define target segments, create differentiated advantages for served target segments and establish distinctive positions in relation to main competitors.

Some authors, such as Craven and Shipp (1991), bringing in discussion the concept of capabilities of market-oriented organization, referring to the ability of market knowledge, flexibility, strategic view and develop lasting relationships with all external stakeholders (Craven, Shipp, 1991). In fact, organizational capabilities refer to: skills, through the interfunctional operational teams, gained knowledge through experience in market orientation, coordination of activities, facilitated by formal and informal communication. More simplified approach to market orientation are given by Deshpande, Farley, Webster, F. (1993) and Shapiro (1988): ,a set of beliefs that put consumer interests before”; ,coordinated implementation of interoperable resources in order to create a superior value to the consumer".

Marketing literature describes market-orientation as a process by which organizations obtain, process and disseminate information about consumers and competitors throughout the organization and act on such information. This market orientation is defined broadly in terms of consumer activities (Day, 1990, Kohli and Jaworschi, 1990, Deshpande, Farley, Webster, 1993; Jaworschi and Kohli, 1993) or synthetic, in terms of a balance between customers and competitors (Day, 94, Narver and Slater, 1990, etc.).

What is the importance of market orientation of the organization? Specialized research showed that, in general, market-oriented organizations gain better efficiency compared to leading competitors that have not incorporated that vision (Ames, Hlavacek, 1990). Although studies do not specify clear reasons that allow market-oriented organizations to achieve a surplus above the threshold of profitability made by most competitors, there are some elements that are considered important: the efficiency of investment, market-oriented organization has the ability to understand importance of investment in marketing activities; involvement and satisfaction of human resources, factors that are both cause and effect of consumer satisfaction; increased revenue; competitive preemption; superior satisfaction deliver to target segments, organization removing obstacles cannot easily be overcome by competitors. These barriers can be both psychological (the consumer is satisfied with the relationship with the organization and choose to resist to changes) and economic (financial risks generated by changing the brand). 


\section{Instead of conclusions}

Despite these arguments of reinvention of marketing function, there are theories in marketing literature that reveal a degree of skepticism about its value in the future. In this respect, we refer to Brown`s theory (1995), which proposes 4 stages of acceptance of the concept and of the marketing approach, as follows (Brown, 1995):

- first level, that of achieving, is characterized by a general acceptance of the concept of marketing, but that often raises implementation problems; the most common manifestation of this phase is related to acceptance and ownership by the managers of the concept and of the marketing approach. Clear effects of this phase, for the many organizations, are the concern to make marketing approach operational in an organizational environment characterized by antagonistic relationships and inter-functional rivalry and centering efforts on identifying internal marketing programs to facilitate necessary organizational change.

- the second stage, the intensive development, where marketing concept, already assumed, faces circumstances when it is considered to be rather inadequate or with poor relevance, it is about market sectors and markets where the role and contribution of marketing are low and where there are significant imbalance between supply and demand - government, underdeveloped markets, etc.

- the third stage, that of rearrangement, requires a fundamental reorganization of marketing concept as a measure to adjust it more quickly and easier to different market realities. In this sense, Webster (1988), starting from the necessity of differentiating between the marketing and marketing management, believes that "marketing should return to its basic foundation orientation toward the consumer ... in the detriment of myopic concerns - orientation toward increasing market share".

- the fourth stage, and most radical, is the retaliation one, which according to Brown, provides very useful information in estimating the future value of marketing: “... marketing approach has not always had success in order to lose effectiveness today. Despite the recent success of marketing approach, the high rate of failure in the process of launching new products recorded the highest threshold of all time".

\section{References}

1. Ames, Ch., Hlavacek, J. (1990), Market driven management, Journal of Marketing, vol. 54, issue 2, april.

2. Brady, J., Davis, I. (1993), Marketing in Midlife Crisis, The McKinsey Quarterly, issue 2.

3. Brown, S. (1995), Post-Modern Marketing, Routledge, London.

4. Brownlie, D.T., Saren, M.A. (1992), The four Ps of the marketing concept, prescriptive, polemical, permanent and problematic, European Journal of Marketing, vol. 26, issue 4.

5. Christopher, M.G., Payne, A., Ballantyne, D. (1991), Relationship Marketing: Bringing quality customer service and marketing together, Butterworth-Heinemann.

6. Cooper, R.G. (1993), Winning at New Products, Reading, Mass, Addison Wesley Publishing Company.

7. Craven, D.W., Shipp, S.H. (1991), Market driven strategies for competitive advantage, Business Horizons, vol. 34, issue 1, january-february.

8. Day, G. (2001), Market driven winners. Symphonya Emerging Issues in Management, Ed. Dipartimento di Scienze Economico Aziendali, Milano, issue 2.

9. Day,G.S. (1990), Market driven Strategy: Processes for Creating Value, Free Press, New York.

10. Deshpande, R., Farley, J., Webster, F. (1993), Corporate Culture, Customer Orientation and Innovativeness in Japanese Frims: A Quadrad Analysis, Journal of Marketing, vol. 75, january.

11. Deshpande, R., Farley, J.U. (1998), Measuring Market Orintation: Generalisation and Synthesis, Journal of Market Focused Management, vol. 2.

12. Dwyer, F.R., Schurr, P.H., Sejo, Oh. (1987), Developing Buyer-seller Relationship, Journal of Marketing, vol. 51, april. 


\section{Studies and Scientific Researches - Economic Edition, no. 15, 2010}

13. George, M., Freeling, A., Court, D. (1994), Reinventing the Marketing Organisation, The McKinsey Quarterly, issue 4.

14. Gummeson, E. (1987), The new marketing - developing long-term interactive relationships, Long Range Planning, vol. 20, issue 4.

15. Hooley, G.J., Lynch, J.E. (1985), Marketing lessons from the UK's high-flying companies, Journal of Marketing Management, vol. 1, issue 1.

16. Hooley, G.J., Saunders, J.A. (1993), Competitive Position: The Key to Market Strategy, Prentice Hall Internationla, London.

17. Kohli, A.K., Jaworschi, B.J. (1990), Market Orientation: The Construct, Research Propositions and Managerial Implication, Journal of Marketing, vol. 54, april.

18. Kohli, A.K., Jaworscki, B.J.,Kumar, A. (1993), MARKOR: a measure of market orientation, Journal of Marketing Research, vol. 30, novembre.

19. Lambin, J.J. (1996), The Misunderstanding About Marketing, CEMS Businees Review, vol. 1, issue 1.

20. Lash, M.L. (1990), The Complete Guide to Customer Service, New York, John Wiley and Sons.

21. Nagle, T.T., Holden, G. (1994), The Strategy and Tactics of Pricing, Englewood Cliffs, New Jersey, Prentice Hall.

22. Narver, J.C., Slater, S.F. (1990), The Effect of a Market Orientation on Business Profitabi1ity, Journal Of Marketing, vol. 54, october.

23. Noble, C.H., Sinha, R.K., Kumar, A. (2002), Market Orientation and alternative strategic orientation: a longitudinal assessment of performance implications, Journal of Marketing, vol. 66, october.

24. Piercy, N.F. (1991), Market-led Strategic Change, Thorsons, London.

25. Porter, M.E. (1985), Competitive Advantage, New York, The Free Press.

26. Rapp, S., Collins, T.L. (1990), The Great Marketing Turnaround: The Age of the Individual and How to Profit from It, Prentice Hall.

27. Shapiro, B.P. (1988), What the Hell is „Market Oriented”, Harvard Business Review, vol. 66, issue 6.

28. Tadepalli, R., Avila, R.A. (1999), Market Orientation and the Marketing Strategy Process, Journal of Marketing Theory and Practice, spring.

29. Thomas, M.J. (1993), Marketing - in chaos or trannsition?, in Brownlie, D., - Rethinking Marketing, Warwick Business School Research Bureau.

30. Webster, F.E. (1999), Is your company real1y market driven?, Financial Times Mastering Global Business, Pitman Publishing, London.

31. Webster, F.E. (1988), The rediscovery of the marketing concept, Businees Horizons, vol. 31, issue 3 .

32. Wilson, R.M.S, Fook, N.Y.M. (1990), Improving marketing orientation, Marketing Business, vol. 11.

33. Wong, V., Saunders, J.A. (1993), Business orientation and corporate success, Journal of Strategic Marketing, vol.1, issue 1. 